This item was submitted to Loughborough's Research Repository by the author.

Items in Figshare are protected by copyright, with all rights reserved, unless otherwise indicated.

\title{
Dynamic multilevel modelling of industrial energy demand in Europe
}

\section{PLEASE CITE THE PUBLISHED VERSION}

https://doi.org/10.1016/j.eneco.2018.06.001

\section{PUBLISHER}

Elsevier

\section{VERSION}

AM (Accepted Manuscript)

\section{PUBLISHER STATEMENT}

This paper was accepted for publication in the journal Energy Economics and the definitive published version is available at https://doi.org/10.1016/j.eneco.2018.06.001

\section{LICENCE}

CC BY-NC-ND 4.0

\section{REPOSITORY RECORD}

Sharimakin, Akinsehinwa, Anthony Glass, David Saal, and Karligash Glass. 2019. "Dynamic Multilevel Modelling of Industrial Energy Demand in Europe". figshare. https://hdl.handle.net/2134/33659. 


\title{
Dynamic Multilevel Modelling of Industrial Energy Demand in Europe
}

\author{
Akinsehinwa Sharimakin*, Anthony J. Glass, David S. Saal, Karligash Glass
}

\begin{abstract}
Previous studies of industry level energy demand have not accounted for the hierarchical nesting of industries within a system that also adequately allows for country specific determinants of energy demand. The principal contribution of this paper is therefore to analyse energy demand for European industries over the period 1995-2007 using a dynamic multilevel model that accounts for this hierarchical data structure. Among other things, we find, firstly, that our dynamic multilevel model suggests that if industry income and the industry energy price increase by $10 \%$, long run energy demand will increase by $8.1 \%$ and fall by $6.8 \%$, respectively. Secondly, we find that the corresponding long run income and price elasticities are substantially larger in a standard dynamic model of industry level energy demand which does not account for the hierarchical data structure. Our results therefore suggest that not accounting for the hierarchical data structure results in unreliable estimates of energy demand elasticities. From a policy perspective we argue that it is imperative that future industry level energy demand studies account for the hierarchical structure of the data. This is to prevent energy policy making being based on industry level evidence that substantially inflates the responsiveness of long run energy demand to income and price changes.
\end{abstract}

Keywords: Multilevel modelling, Industrial energy demand, European countries, Long-run elasticities.

JEL classification:

$\mathrm{C} 2$

D2

Q4

* Corresponding author, School of Business and Economics, Loughborough University, United Kingdom. Email: A.Sharimakin@lboro.ac.uk 
The estimated long-run elasticities derived from energy demand functions have retained energy demand modelling as an area of interest in the literature. This is because these elasticities serve as important tools for the policy makers in making appropriate predictions about future energy use and energy related policies, Hunt and Ninomiya (2005). This subsequently highlights the potential implications of energy related policies based on inaccurate energy demand estimates, which are very likely to be misleading or inappropriate. Numerous approaches have been employed to derive energy demand estimates ranging from aggregate level to sectoral level analyses, but, majority of the existing literature generate their energy demand estimates from aggregate demand models ${ }^{1}$. Although, energy demand estimates derived from aggregate energy demand functions are useful in formulating macroeconomic policies related to energy security and carbon emissions, but such analysis fails to capture the potentially more diverse energy consumption behaviour of disaggregated units in the economy. Consequently, detailed information and understandings required in formulating specific energy related policies are lost (Bhattacharyya, 2011). This in turns highlights the importance of estimating industrial energy demand as it avoids masking the differences in the production process across the various productive sectors.

The purpose of this paper is to analyse industrial energy demand across 29 European countries over the period 1995-2009. The main contribution of this paper over the existing literature in industrial energy demand modelling is the introduction of the dynamic multilevel model that controls for the hierarchical structure of industry level data. Given that failure to control for the multilevel structure of hierarchical dataset could produce unreliable estimates, Steenbergen and Jones (2002). The methodology adopts in this paper subsequently highlights the implications of ignoring the hierarchical structure of industry level data while modelling industrial energy demand. Specifically, we analyse energy demand function for the sectors as a whole and for different sector types by classifying the sectors into primary, manufacturing and service sectors respectively. The categorising of the whole sample into three different sectors allows the estimation of price and income elasticities for each of the sectors, which in turn provide insightful information in formulating specific sector's energy related policies. The estimation method employed in this paper is sensible as Lee (1997) demonstrates that the estimates from a model using only aggregated industrial data might be biased.

\footnotetext{
${ }^{11}$ Lee and Lee (2010) list studies that have estimated aggregate energy demand function. In addition; York (2007), Adeyemi et al. (2010) and Lee and Chiu (2011) estimate aggregate energy demand function.
} 
The remainder of this paper is organised as follows. Section 2 presents the overview of existing literature in industrial energy demand. Section 3 introduces the dynamic multilevel econometric methodology and discusses our application of it to industrial energy demand. Section 4 describes the data used for the estimations. The empirical results are then discussed in Section 5. Section 6 presents the concluding remarks and avenues for further research.

\section{$2 \quad$ Related Literature}

The research interest in modelling industrial energy demand has increased in recent years owing to the fact that industrial energy consumption accounts for about one third of the global energy consumption (Greening et al., 2007). Further, as noted by Agnolluci et al. (2017) the contribution of industrial energy consumption to global energy consumption has remained constant over the years fluctuating around 33\% and 27\% in 1971 and 2013 respectively (IEA, 2016). In the last three decades, tremendous efforts have been taken to empirically model industrial energy demand. The closest relatives to this paper falls into two categories: (i) empirical modelling of industrial energy demand using a system of cost share with a translog specification and (ii) empirical modelling of industrial energy demand using a single-equation model ${ }^{2}$. In respect to the former, existing literature in industrial energy demand modelling primarily focuses on the elasticities of substitution (ES) and complementarity (EC) between factor inputs/or fuel types owing to the seminar work of Berndt and Wood (1975). Among others, Berndt and Wood (1975), Fuss (1977), Anderson (1981), Prywes (1986), Arnberg and Bjøner (2007) and Tovar and Iglesias (2013) find capital and energy to be complements. However, some existing studies on industrial energy demand refute the claim that capital and energy are substitutes, and therefore argue that capital and energy are complements. These include Griffin and Gregory (1976), Uri (1982), Kim and Heo (2013), Haller and Hyland (2014), Lin and Ahmad (2016) and Li and Lin (2016).

In addition to the analysis of factor substitution, some studies simultaneously highlight the importance of the price elasticities. Floros and Vlachou (2005) estimated the Greek industrial energy consumption using a two-stage translog model for the period 19821998. Their results suggest that energy price elasticities vary markedly between -1.13 and 0.02 , with upper bound decreasing to -0.04 when the model only contains statistically significant elasticities. Kim and Heo (2013) estimate a translog cost function for the

\footnotetext{
${ }^{2}$ We classified models that are not system cost-share translog models such as fixed effect, random effect models and GMM etc. as single-equation model.
} 
manufacturing sectors of 10 OECD countries and find energy price elasticities to be inelastic ranging between -0.08 and -0.76 . Haller and Hyland (2014) also employ translog function to model production in the Irish manufacturing sector over the period 1991-2009 and find price to be elastic with an estimated elasticity -1.46 . Similarly, Li and Lin (2016) estimate both static and dynamic tranglog cost function to analyse inter-factor/inter-fuel substitution in China over the period 1985-2012. The authors find own price elasticities for electricity, coal, and oil to be $-0.72,-0.76$ and -0.74 respectively. We acknowledge that the system based estimation of the translog cost model has remained a popular method to model industrial energy demand, because of the flexibility of the translog specification as well as this approach is consistent with microeconomic theory related to cost minimization. However, notwithstanding this popularity, most of the studies that model industrial energy demand using cost functions mainly focus on inter-factor and/or inter-fuels substitution possibilities rather than energy price or income/output estimates.

In contrast, studies that have modelled industrial energy demand with the single-equation model have focused more on investigating the implication of energy price and economic activity on energy demand by estimating long-run energy price and economic activity elasticities of energy demand. Bjøner and Jensen (2002) employ fixed effect model to analyse the survey data for 8 Danish industrial companies between 1983 and 1997. They find average price elasticity -0.44 for the whole industry, while price elasticities vary between industries ranging from -0.69 and -0.21 . The elasticities of economic activity vary between 0.44 and 0.65 with an average of 0.54 for the whole industry. The elasticities of energy price and economic activity produce by Agnolluci et al. (2017) are almost identical as the authors find average elasticities with respect to energy price -0.41 and economic activity 0.57 for UK industrial subsectors. These average elasticities are somewhat similar to the average elasticities with respect to energy price and economic activities produce in Agnolucci (2009, 2010). Hunt et al. (2003a) demonstrate the importance for allowing for inherent underlying forces that can be stochastic in nature in energy demand modelling. Structural Time Series Model (STSM) of Harvey (1989) was used to estimate energy demand for the UK as a whole and for different sectors using a quarterly data for the period 1971q1 to 1997q4. Their findings suggest that energy demand models that fail to allow for these underlying forces are likely to produce biased estimates. In a very similar study, Dimitropolous et al. (2005) reconfirmed the importance for allowing for the inherent underlying forces in industrial energy demand modelling using an annual UK data for the period 1967-2002 across different 
sectors. They find the elasticity with respect to energy price between -0.11 and -0.23 and the elasticity with respect to economic activity between 0.34 and 0.81 . Similarly, Dilaver and Hunt (2011) investigate the impacts of energy price and economic activity on the Turkish industrial electricity consumption using STSM. Having controlled for the underlying forces that could affect electricity consumption in the model; they find both output and price to be inelastic with estimated elasticities 0.15 and -0.16 respectively- value close to Dimitropolous et al. (2005) when considering only price.

One strand in the literature of energy demand argues that there is a difference between the impacts of an increased energy price and a decreased energy price- the concept of asymmetric methodology introduced by Dargay and Gately (1995). With respect to industrial energy demand, Adeyemi and Hunt (2007) consider the APR methodology to demonstrate that the use of single-equation model had become a standard procedure while modelling industrial energy demand for a panel of 15 OECD countries. They argue on the basis that the procedure is simple, straightforward and required limited data. The long-run elasticities with respect to economic activity for the two models estimated are 0.76 and 0.56 . The estimated long-run price elasticity when assuming no asymmetric response is -0.22 , though not statistically significant; when assuming asymmetric price responses, the elasticities for price-maxima, price-recoveries and price-cuts are $-0.52,-0.68$ and -0.30 respectively. In a similar approach, Adeyemi and Hunt (2014) use the same set of 15 OECD countries explored in Adeyemi and Hunt (2007) to model the industrial energy demand using time series analysis over the period 1962-2010. The authors account for both APR and underlying trend in their models, and find estimated long-run income elasticities in the range of 0.34 to 0.96 ; estimated long-run pricemaximum elasticities in the range of -0.06 to -1.22 ; estimated long-run price-recovery elasticities in the range of 0.00 to -0.27 ; and estimated long-run price-cut elasticities in the range of 0.00 to -0.18 .

Two key points can actually be drawn from the literature. First, existing literature on industrial energy demand that in principle heavily rely on industry/sectoral level data do not normally account for the hierarchical structure of the industry level data used and consequently likely to produce unreliable estimates. Second, despite the huge existing literature on energy demand modelling, studies primarily focusing on European industrial energy demand remain relatively scarce in the literature given the fact that most previous 
studies rather focused on modelling energy demand for OECD countries ${ }^{3}$ or a single country. Therefore, first, this paper aims to contribute to the existing literature by estimating industrial energy demand with a dynamic multilevel model. Multilevel model is very popular among social scientists and has been widely used in other branches of economics. For instance, in education economics, Konishi et al. (2010), Ronfeldt et al. (2013) and Voyer and Voyer (2014) have employed multilevel model to analyse the determinants of student achievement. Moreover, multilevel modelling has been widely used in social and health economics to analyse the relationship between social capital and health (Islam et al., 2006; Mohnen et al., 2011; Layte, 2011; Murayama et al., 2012). In regional economics, multilevel model has also been used to control for the nesting of regions within countries (Srholec, 2007; Rentfrow et al., 2013). Given the wide use of multilevel models in other branches of economics, we can conclude that multilevel model is in fact an established method of analysis in economics, the benefits of which are transferable to energy economics. Second, we extend the existing literature by modelling the European industrial energy demand.

\section{$3 \quad$ Empirical Method}

\subsection{Multilevel Modelling}

Multilevel modelling aims to model the relationship between a response variable and a set of explanatory variables, but differs from standard regression analysis by modelling units of observation at different 'levels'. In particular, multilevel analysis is applied to a hierarchical data structure. For instance, in the context of this study, we have a longitudinal data ${ }^{4}$ that is viewed as three-level or clustered data with occasions (that is, time period) nested in subjects (that is, industries) which are in other hand nested in countries. Following Rabe-Hesketh and Skrondal (2012) we use the term “occasions” $i$ for level-1 units, "industries” $j$ for level-2 units and "countries" $k$ for level-3 units. In other words, this implies that the individual observations are in general not absolutely independent. That is, industries interact with and are influenced by the economic environment to which they belong, and that national economies are in turn influenced by the industries that make them up.

More importantly, one can associate differences in energy consumption between industries to the countries where they are located, but industries located in different countries

\footnotetext{
${ }^{3}$ In addition to the studies mentioned above, Hass et al. (1998), Griffen and Schulman (2005) Filippini and Hunt, (2011) and Lee and Chiu, 2013) have also modelled energy demand for OECD countries.

${ }^{4}$ For interested reader on multilevel modelling for longitudinal or repeated measures data see Rabe-Hesketh and Skrondal (2012).
} 
may have different energy consumption behaviour even though they have similar industrial features. This could arise as a result of diversity in energy prices, climate, economic growth and technological progress across countries. In other words, the energy consumption behaviour of a typical industry operating in a given country can be influenced by the consumption behaviour of another industry operating in a different country. In other hand, industries located in the same country tend to have common energy consumption behaviour even though they have different industrial characteristics given the fact they face the similar economic and social situations. This could be referred as the consumption patterns of clusters, that is, industries with different characteristics. Steenbergen and Jones (2002) discuss the statistical problems inherent in clustered data and demonstrate that models that do not control for this clustering tend to produce unreliable estimates in terms of incorrect standard errors.

In this paper, we control for clustering in our data by using multilevel model that can explicitly accounting for the multilevel structures of the data. Multilevel modelling allows us to disentangle the clustering at different levels by including the explanatory variables and the disturbance term at every level. That is, our models incorporate predictors at each of the levels. This allows us to indirectly control for the heterogeneity of the relationships between the response variable and the explanatory variables among clusters- of industries and countries. Consequently, we are able to identify the unexplained heterogeneity associated with each level. Another advantage of using multilevel regression is to remove the "Robinson effect” after Robinson (1950). This is often referred as dis-aggregation bias or ecological fallacy where an analyst wrongly analyses data at one level and formulates conclusions at another level. Hox et al. (2010, pp. 2-4) discusses the major statistical problem associated with this Robinson effect by arguing that when data is aggregated substantial information about underlying economic relationships is lost and the statistical analysis loses power, leading to a high potential for spurious results. Multilevel modelling is therefore explicitly designed to remove this biasedness as it provides a tool for analysing hierarchical data structures.

\subsection{Dynamic Multilevel Modelling of Industrial Energy Demand}

The microeconomic model underlying our econometric specification of European industry energy demand is a modification of Medlock (2009) and is specified as follows, where $i$ is a time index, $j$ is an industry index and $k$ is a country index:

$$
E^{*}=E\left(Y, P, D_{i}\right)
$$


where $E^{*}$ is the energy demand, $Y$ is output, $P$ is the price of energy and $D_{i}$ is the time dummies. We acknowledge that some existing literature considered the methodology of APR (Adeyemi et al., 2010; Adeyemi and Hunt, 2014) on the basis that there is a difference between the impacts of an increased energy price and a decreased energy price. Although, Griffin and Schulman (2005) refute this claim by arguing that the APR is only capturing energy saving technical progress endogenously, but Huntington (2006) replied by arguing that there is role for both the APR and technical progress while estimating energy demand model. In this paper, we are in favour of the former (Griffin and Schulman, 2005) as we do not considered APR like some existing literature on energy demand such as Hunt et al. (2003); Agnolucci, (2009, 2010); Lee and Lee (2010) and Lee and Chiu (2013). In a separate strand of the literature, the importance of allowing for the underlying nonlinear forces related to energy consumption has been considered ${ }^{5}$ (Hunt et al., 2003a; Dimitropoulous et al., 2005) with a mechanism termed as Underline Energy Demand Trend (UEDT) ${ }^{6}$. As noted by Adeyemi et al., (2010), the UEDT is regarded as a measure of energy saving technical progress and is captured by the time dummies in a panel data analysis, following the argument of Griffin and Schulman (2005). Following these arguments and the importance of allowing for the technical progress in energy demand model, we allow for the UEDT in our analysis and is captured by the time dummies, $D_{i}$.

We employ a dynamic multilevel model (DMM hereafter) and generalised method of moments (GMM hereafter) estimators (Arellano and Bond, 1991) ${ }^{7}$ in estimating Eq. (1). However, we only discuss the DMM as the GMM has been extensively used and explicitly discussed in the literature. Given the structure of our dataset- a hierarchical structure with a balanced panel of multiple years of data on industries nested within countries, we apply a 3level dynamic multilevel model in estimating European industrial energy demand where the numbers of occasion are regarded as level-1, the industries as level-2 which are nested in countries, level-3. Given our fully balanced panel data base, the general 3-level DMM is specified as follows:

\footnotetext{
${ }^{5}$ We are grateful to an anonymous referee for pointing this out.

${ }^{6}$ Hunt et al., (2003a) demonstrate the importance of allowing for inherent underlying forces that are nonlinear to energy demand and argue that any energy demand model that fail to allow for these nonlinear forces might produce biased estimates.

7 The GMM is recognised as the baseline model for comparison. The GMM is known for controlling for endogeneity in the model and we also control for the unobserved country- and time-specific effects by including country dummies and time dummies. The industry-specific effects are automatically control for in the GMM given the fact that the industries represent our identifiers.
} 
$E_{i j k}=\alpha E_{i-1, j k}+X_{k}^{(3)} u_{k}^{(3)}+X_{j k}^{(2)} u_{j k}^{(2)}+D_{i j k}+\epsilon_{i j k}$

where $k=1, \ldots, K, j=1, \ldots, J_{i}$, and $i=1, \ldots, I_{j k}$. $D_{i j k}$ is the time dummies. For example, the dependent variable $E_{i j k}$ denotes the energy consumption for industry $j$ operating in country $k$ in time period (or occasions) $i$. Each $j$ and $k$ group consists of $i$ observations, while $E_{i j k}$ and $\epsilon_{i j k}$ each have row dimension $I . X_{k}^{(3)}$ is the $I \times K$ design matrix for the thirdlevel random effects $u_{j}^{(3)}$, and $X_{j k}^{(2)}$ is $J \times K$ design matrix for the second-level random effects $u_{j k}^{(2)}$. The random terms are assumed to be identically independently distributed

$$
u_{k}^{(3)} \sim N\left(0, \sigma_{v}^{2}\right) ; \quad u_{j k}^{(2)} \sim N\left(0, \sigma_{u}^{2}\right) ; \quad \epsilon_{i j k} \sim N\left(0, \sigma_{\epsilon}^{2}\right)
$$

For the purpose of estimation, we redefined Eq. (2) through a three-stage formulation using the notation of Bryk and Raudenbush (1992). The level-1 model for occasions $i$, industry $j$, and country $k$ is a linear regression on time and is specified as:

$E_{i j k}=\pi_{0 j k}+\pi_{1 j k} D_{i j k}+\varepsilon_{i j k}$

where $D_{i j k}$ is the time dummies and $\varepsilon_{i j k}$ is the level-1 residual. The intercept $\pi_{0 j k}$ in the level-1 model vary between industries according to the following level-2 model:

$\pi_{0 j k}=\alpha_{00 k}+\alpha_{01} E_{i-1, j k}+\alpha_{02} Y_{j k}+\alpha_{03} P_{j k}+\delta_{0 j k}$

where $E_{i-1, j k}$ is one period lagged value of energy use, $Y_{j k}$ stands for output at industry-level, $P_{j k}$ energy price at industry-level and $\delta_{0 j k}$ is a level-2 random intercept. Further, we can introduce the country-level predictors by modelling the industry-level intercept, $\alpha_{00 k}$ :

$\alpha_{00 k}=\beta_{000}+\beta_{001} Y_{k}^{c}+\beta_{002} P_{k}^{c}+v_{0 k}$

where $Y_{k}^{c}$ stands for output at country-level, $P_{k}^{c}$ energy price at country-level and $v_{0 k}$ is a level-3 random intercept.

Substituting the level-3 model into the level-2 model gives

$$
\pi_{0 j k}=\beta_{000}+\beta_{001} Y_{k}^{c}+\beta_{002} P_{k}^{c}+\alpha_{01} E_{i-1, j k}+\alpha_{02} Y_{j k}+\alpha_{03} P_{j k}+v_{0 k}+\delta_{0 j k}
$$


By making assumptions that the effect of industry-level variables are fixed (i.e., $\alpha_{0 x}=\beta_{01 x}$ for $x=0$ ) and that the effect of the level-1 variable is fixed as well (i.e., $\pi_{1 j k}=\beta_{100}$ ), then the substitution of level-2 model into level-1 model results to our 3-level model given as:

$$
\begin{aligned}
E_{i j k}= & \beta_{000}+\beta_{001} Y_{k}^{c}+\beta_{002} P_{k}^{c}+\beta_{010} E_{i-1, j k}+\beta_{020} Y_{j k}+\beta_{03} P_{j k}+\beta_{100} D_{i j k}+v_{0 k}+ \\
& \delta_{0 j k}+\varepsilon_{i j k}
\end{aligned}
$$

where $v_{0 k} \sim N\left(0, \sigma_{v}^{2}\right), \delta_{0 j k} \sim N\left(0, \sigma_{u}^{2}\right)$ and $\varepsilon_{i j k} \sim N\left(0, \sigma_{\varepsilon}^{2}\right)$.

This model has unique features as it brings together the predictor at different levels and it assumes that the error terms are uncorrelated across levels. A typical multilevel model normally consists of two parts: the fixed part, which shows the relationship between the predicted value of the dependent variable and the explanatory variables, and the random part, which shows the estimates of the group effects on the response variable. In principle, by simply including the lagged of the dependent variable into a static model such as Eq. (7), we are making a very strict assumption of no correlation between the lagged response and the residuals (that is, $\operatorname{Cov}\left(\varepsilon_{i j k}, E_{i-1, j k}\right)=0$ ). Therefore, estimating Eq. (7) directly without correcting for the potential correlation between the residuals and the lagged dependent variable is a very naïve way of estimating a dynamic model and this may consequently lead to biased and inconsistent estimates (Nickell 1981). ${ }^{8}$ This is described as the problem of initial conditions in the literature. However, Steele (2008) and Crouchley et al. (2009) have argued that the problem of initial conditions is difficult to justify in practice as it only arises if the length ' $T$ ' period of the study is relatively small because the problem is wiped out over a relatively long period of time. That is, in a longitudinal study with a relatively long time period, the problem of initial conditions might not occur. But unfortunately, none of these papers suggest an appropriate time period that is long enough for the problem of initial conditions not to be of concern. Given the above argument, we control for the potential correlation that might occur between the lagged dependent variable and the residuals by adopting the joint working models proposes by Heckman (1981a) following Skrondal and Rabe-Hesketh (2014) ${ }^{9}$.

\footnotetext{
${ }^{8}$ By ignoring the possibility of correlation between the dependent variable and the residuals and estimate Eq. (7) might lead to upward biasedness of the coefficient of the state dependency $\left(\beta_{010}\right)$ and the downward biasedness of the estimate of the unobserved heterogeneity $\sigma_{v 0}^{2}$.

${ }^{9}$ The approaches discuss in this paper are for binary response models, but they can also be adopted for continuous response models. Moreover, interested readers may see Kazemi and Crouchley (2006), Crouchley et al. (2009; Chapter 11) for other approaches.
} 
The problem of initial condition arises when response at initial period does not coincide with the start of the process under study. In theory, response at the initial period $E_{0 j k}$ plays a crucial role in dynamic/transition models as subsequent responses (i.e., $E_{1 j k}, E_{2 j k}, \ldots, E_{n j k}$ ) depend on it ${ }^{10}$. The basic idea of Heckman (1981a) is to model the initial response, jointly with the subsequent responses. In practice, Eq. (7) is a as model at a later occasion (i.e., when $i=1, \ldots, I-1)$ and since we have on-going data process where initial response $E_{0 j k}$ is considered to be affected by random intercept $\delta_{0 j k}$ and pre-sample $E_{-1, j k}$ response, thus, there is need to jointly model initial response $E_{0 j k}$ and subsequently responses. An unrefined starting point would be to specify a similar version of Eq. (7) using the initial response $E_{0 j k}$ as the dependent variable as a function of the predictors, but without the lagged response and the time dummies, since we only have initial time period here. This model is regarded as when $i=0$ can be specified as:

$E_{0 j k}=\gamma_{000}+\gamma_{001} Y_{k}^{c}+\gamma_{002} P_{k}^{c}+\gamma_{020} Y_{j k}+\gamma_{03} P_{j k}+v_{0 k}+\delta_{0 j k}+\varepsilon_{0 j k}$

where $v_{0 k} \sim N\left(0, \sigma_{v}^{2}\right)$ and $\delta_{0 j k} \sim N\left(0, \sigma_{u}^{2}\right)$ as given above, and $\varepsilon_{0 j k} \sim N\left(0, \sigma_{0 \varepsilon}^{2}\right)$.

It is important to point out that the remaining disturbance terms at subsequent period, that is, $i>0$ and the initial period, that is, $i=0$ are not equal (that is $\sigma_{\varepsilon}^{2} \neq \sigma_{0 \varepsilon}^{2}$ ). This is simply because the variance of the residuals of subsequent responses $E_{i j k}$ condition on the covariates $\boldsymbol{X}_{i j k}$ and the lagged response $E_{i-1, j k}$ is different from the variance of the residual of initial responses $E_{0 j k}$ which is condition on the covariates $\boldsymbol{X}_{0 j k}$ only. In other words, the residual in the initial period is related to the explanatory variables of initial period, while the residuals of the subsequent period are related to the explanatory variables at subsequent period, $\boldsymbol{X}_{i j k}$ and the lagged response, $E_{i-1, j k}$. Since Eq. (8) for initial response $E_{0 j k}$ and Eq. (7) for response $E_{i j k}$ shared the same industry (i.e., $\delta_{0 j k}$ ) and country (i.e., $v_{0 k}$ ) random effects therefore, they must be jointly estimated.

For estimation purposes, we create time period indicators that distinguishes the initial period $(i=0)$ coded as $w_{1}$ from the subsequent periods $(i>0)$ coded as $w_{2}$. The time period indicator $w_{1}$ is coded as 1 for $i=0$ and 0 otherwise. The time period indicator $w_{2}$ is coded as 1 for $i>0$ and 0 otherwise. Then, we interact $w_{1}$ with the predictors in Eq. (8) and interact $w_{2}$

${ }^{10}$ See appendix A1 for the technical notes. 
with the predictors in Eq. (7). Both models for $i=0$ and $i>0$ are therefore jointly specified as one model as follows:

$$
\begin{aligned}
E_{i j k}=\gamma_{000} w_{1} & +\gamma_{001} w_{1} Y_{k}^{c}+\gamma_{002} w_{1} P_{k}^{c}+\gamma_{020} w_{1} Y_{j k}+\gamma_{03} w_{1} P_{j k}+\beta_{000} w_{2}+\beta_{001} w_{2} Y_{k}^{c} \\
& +\beta_{002} w_{2} P_{k}^{c}+\beta_{010} w_{2} E_{i-1, j k}+\beta_{020} w_{2} Y_{j k}+\beta_{03} w_{2} P_{j k}+\beta_{100} w_{2} D_{i j k}+v_{0 k} \\
& +\delta_{0 j k}+\epsilon_{i j k}
\end{aligned}
$$

where $v_{0 k} \sim N\left(0, \sigma_{v}^{2}\right), \delta_{0 j k} \sim N\left(0, \sigma_{u}^{2}\right)$ and the estimated variance for level-1 residual $\epsilon_{i j k}$ is decomposed into $\varepsilon_{0 j t} \sim N\left(0, \sigma_{0 \varepsilon}^{2}\right)$ and $\varepsilon_{i j t} \sim N\left(0, \sigma_{\varepsilon}^{2}\right)$ by defining groups based on $w_{1}$. It is worth pointing out that model 7,8 and 9 are interrelated by substitution. If $w_{1}$ and $w_{2}$ are substituted as 0 and 1 respectively into Eq. (9) that gives Eq. (7), and If $w_{1}$ and $w_{2}$ are substituted as 1 and 0 respectively into Eq. (9) that gives Eq. (8). Ultimately, the model of interest is model 7 when $i>0$, that is, when $w_{1}=0$ and $w_{2}=1$ in Eq. (9) as it relates to the time period of our analysis. The inclusion of model 8, (i.e., when $i=0$ ) becomes imperative only for controlling for the initial conditions problem. Hence, only the results for $i>0$ in Eq. (9) will be presented in the analysis section.

\section{$4 \quad$ Data}

The main source of data for our analysis is World Input-Output Database (Timmer et al., 2015) ${ }^{11}$. The WIOD is based on national accounts data and it provides a comprehensive, harmonized dataset that allows comparison of specific environmental indicators like sectoral energy use over the years covered by the database (1995 to 2009). The WIOD has two advantages with respect to existing data sources as suggested by Voigt et al. (2014) ${ }^{12}$. First, the harmonization procedures undertaken throughout the data collection minimize the risks of measurement errors. Moreover, the consistence in data collection and comparability across countries describes the data efficiency gains at the sectoral and global levels. Second, the WIOD provides data on sectoral price deflators. This allows for the retaining of important information and variations with respect to price development, which is an advantage over the use of aggregate national price deflators in sectoral analysis.

\footnotetext{
${ }^{11}$ In this paper, we used data from the three major accounts of the WIOD, the National Input-Output Tables (NIOT) released in November 2013, Environmental Accounts (EA) released in March 2012 and the SocioEconomic Accounts (SEA) released in July 2014. Data downloaded from these accounts are available at www.wiod.org

12 Other studies that have also obtained energy data from WIOD include: Hübler and Glas (2014), Kaltenegger et al. (2017) and Loschel et al. (2015).
} 
Our analysis is based on a fully balanced sample of 34 sectors $^{13}$ at three- and four-digit level using International Standard of Industrial Classification (ISIC) Rev.4, which is consistent with NACE Rev.2 across 29 European countries ${ }^{14}$ over the sample period 1995-2009. Data on purchasing power parity exchange rates (US\$) are taken from Penn World Table (PWT 7.1). Industry energy use $(e)$ in terajoule (TJ) is taken from the Environmental Accounts of WIOD, 2012. Industry output is measured as gross output by industry at current market prices in millions of national currency, and data is taken from the Socio-Economic Accounts of WIOD, 2014. To generate the real output $(y)$, we deflated the gross output using the price index of gross output $(1995=100)$ obtained from the SEA of WIOD, 2014. In other to express the real output in international monetary unit, we used the purchasing power parity taken from the Penn World Table (PWT7.1) to convert the real output in national currencies to international units (US\$). Since there is no ready-made data on industry price of energy from data sources, we therefore follow a similar process adopted in Adetutu et al., (2016) to generate the price of energy. The real price of energy $(p)$ is computed as the ratio of energy input expenditure at constant prices in US\$ to energy use in TJ. Energy input expenditure is computed as the addition of the value of expenditure on coke, refined petroleum, nuclear fuel, electricity and gas supply purchased domestically and internationally (millions of US\$). Data on the energy commodities are taken from the National Input-Output Tables (NIOT) of the WIOD, 2013. To derive the real price of energy in US\$, we deflated the energy expenditure by constant unit $(1995=100)$, and then divided the real energy expenditure by energy use in TJ.

Table 1

Descriptive statistics of variables used in the analysis.

\begin{tabular}{llllll}
\hline Description & Variable & Mean & Std. Dev & Min & Max \\
\hline Energy consumption in TJ & $E$ & 117125.8 & 396875.4 & 42.69 & 3109309 \\
Industry real price of energy in US\$ per TJ & $P$ & 1.59 & 2.36 & 0.002 & 16.01 \\
Industry real output in US\$ & $Y$ & 19230.86 & 37032.64 & 11.97 & 206776 \\
Country real price of energy in US\$/TJ & $P^{c}$ & 1.59 & 1.78 & 0.004 & 14.91 \\
Country real output in US\$ & $Y^{c}$ & 19230.86 & 28886.28 & 29.32 & 123375.5 \\
\hline
\end{tabular}

\footnotetext{
${ }^{13}$ In the interest of balanced panel data and reliable estimates, sectors without data on energy use were excluded from our analysis and all the 34 sectors are listed in the appendix.

${ }^{14}$ Austria, Belgium, Bulgaria, Cyprus, Czec Rep, Denmark, Estonia, Finland, France, Germany, Greece, Hungary, Ireland, Italy, Latvia, Lithuania, Luxembourg, Malta, Netherland, Poland, Portugal, Romania, Russia, Slovak Rep, Slovania, Spain, Sweden, Turkey and United Kingdom.
} 


\section{$5 \quad$ Empirical Analysis}

In this section, we discuss the results of the models estimated and all variables estimated are in their natural logarithm. We employ the GMM and DMM to estimate model 9 for all sectors as a whole and also separately for primary, manufacturing and service sectors ${ }^{15}$. For straightforward interpretation, we centred the industry-level variables on the log of their group means (country-level) ${ }^{16}$ so that the coefficients of the industry-level and country-level variables can be interpreted as the within-country (or between-industry) and betweencountries elasticities. We present the parameter estimates of the GMM and DMM estimators in Table 2 and 3 respectively, for the sectors as a whole and in the restricted samples. Unlike the initial DMM (model 7) the GMM does not suffer from the endogeneity problem of the correlation of the lagged response and the disturbance term that could result to a biased and inconsistent estimate. However, the GMM is not an estimator specifically designed to control for cluster-level heterogeneity resulting from hierarchical data and consequently not an estimator suitable to analyse multilevel model. This is simply because the GMM can only automatically control for a given level of heterogeneity at the level of the data in which the identifiers are based on. Since our analysis is based on industry data, therefore our identifiers are based on industry rather than country. This implies that the GMM automatically controls for heterogeneity across industries only and consequently might produce unreliable estimates. Generally, we acknowledged the fact that other unobserved heterogeneity (e.g., countryspecific and time-specific effects in our analysis) could also be controlled for in the GMM by introducing dummies into the estimated models, but the models becomes very unlikely to analyse when the size of the sub-units (e.g country and time period) are very large ${ }^{17}$. Besides, the DMM does not only account for heterogeneity across all the sample units, but also produces random-effect results which provide information about the extent of unobserved heterogeneity across the sample units. Given the above argument, we choose the DMM as our preferred model and hence, we discuss the DMM result in much more detail. Nevertheless, our discussions of the estimated results start with the GMM results.

\footnotetext{
15 The classifications of the sectors into primary, manufacturing and service sectors are listed in the appendix.

${ }^{16}$ Henceforth, we shall interchangeably use contextual variables as country-level variables.

17 This situation is similar to the issue discussed in Wooldridge (2009) when using pooling regression to control for fixed specific-effect.
} 


\subsection{Discussion of the Estimated GMM Results}

The estimated GMM results for model 9 for the sectors as a whole and for different sectors are reported in Table 2. To recap, we account for the country-specific and time-specific effects by incorporating country and time dummies into models estimated. Given the fact that the two-step GMM estimator produces asymptotic efficiency gains over the one-step estimator, especially in large samples; we therefore employ the two-step estimator ${ }^{18}$. As the estimated standard errors from GMM otherwise tend to be underestimated, we use the robust standard error option throughout. As display in Table 2, all estimated models pass all the diagnostic tests (no autocorrelation at first difference, valid instruments and valid overidentifying restrictions) as none of the tests is statistically significant. As pointed out in the empirical model section, we test for the importance for allowing for the underlying nonlinear forces in our model by performing a restriction test between the unrestricted model (that is, models with time dummies) and restricted model (without time dummies) using a $\chi^{2}$-Test. In other words, this imposes the null hypothesis restriction that the coefficients on the time dummies are equal to zero $\left(\mathrm{H} 0: \beta_{100}=0\right)$ that is, there is no importance for allowing for the underlying nonlinear forces in the estimated energy demand models. For all models estimated, our results support the importance for allowing for the underlying nonlinear forces in energy demand model by rejecting the null hypothesis that the coefficients on the time dummies are statistically equal to zero. This result is in line with the outcome suggests by Adeyemi and Hunt (2007 and 2014).

The primary results derived from the estimated GMM are as follows. First, majority of the estimated variables are statistically significant with expected signs across board while none of the intercepts is statistically significant with mix signs and relatively large values. Of course, the negative intercepts would have been difficult to justify, if they were statistically significant as this would have been interpreted that the expected demand for energy by industries with no influence from economic activity and energy price is negative. With the exception of the between-country output elasticity for the primary sector, the statistical significant of all other estimated elasticities suggest that both industry-level and country-level economic activities and energy prices influence industrial energy demand. Further, in general, the values of the between-industry price elasticities and between-country price elasticities are largely not different across the board. This suggests that there is no substantial difference on

\footnotetext{
${ }^{18}$ It is worth noting to point out that we employ one-step estimator to analyse the primary sector energy demand because its sample size is relatively small.
} 
average, between the influence of industry-level energy prices and country-level energy prices on industrial energy use. For the whole sector, the coefficient on the industry-level energy price of about -0.30 suggests that a $1 \%$ increase in within-country energy price is associated with a $-0.30 \%$ reduction in within-country energy use in the short-run. Whereas the coefficient on the country-level energy price of about -0.29 suggests that a $1 \%$ increase in between-country energy price is associated with a $-0.29 \%$ reduction in between-country energy use in the short-run. However, our results suggest otherwise in the case of output elasticities as the coefficients of between-industry and between-country output elasticities differ in most cases across board.

For the estimated long-run elasticities, most of the estimated long-run elasticities are inelastic with majority being statistically significant with expected signs across the board ${ }^{19}$. Specifically to the whole sector, neither the output elasticity (1.41), nor the price elasticity $(-0.91)$ is statistically significant with both relatively have huge values compared to the elasticities derived for different sectors with the exception of service sectors' estimated longrun price elasticity $(-1.21)$. The huge difference in the values of the estimated long-run elasticities for the whole sector, and those derived from sector types is an issue of concern. This is because in principle, the estimated long-run elasticities for the whole sector is expected not to be too far away from the average of the estimated long-run elasticities of the sector types. Our results show that the estimated long-run output elasticity for European industries (1.41) is substantially larger than the average of the estimated long-run output elasticities of the sector types (0.66) by 75\%. Our results also show a similar pattern in the price elasticity as the estimated long-run price elasticity $(-0.91)$ is larger than the average (0.67) of the sector types by about $23 \%$. A possible explanation for the difference in values between the estimated long-run elasticities for the sector as a whole and the sector types may be the fact that the GMM is not an appropriate estimator to analysis data with a hierarchical structure as it fails to appropriately account for the multilevel structure of the data. These results again raise the concern about the appropriateness of GMM in estimating energy demand model using hierarchical data.

\footnotetext{
${ }^{19} \mathrm{We}$ find the coefficient on the lagged response for the service sector to be relatively big compare to other sectors. One possible explanation for this outcome may be the difference among the sectors as the industries in the service sector tend to be more associated with previous energy use.
} 
Table 2

Estimated generalized method of moment (GMM) (standard errors are in parentheses)

\begin{tabular}{|c|c|c|c|c|}
\hline Variables & $\begin{array}{l}\text { All } \\
\text { Sector }\end{array}$ & $\begin{array}{l}\text { Primary } \\
\text { Sector }\end{array}$ & $\begin{array}{l}\text { Manufacturing } \\
\text { Sector }\end{array}$ & $\begin{array}{l}\text { Service } \\
\text { Sector }\end{array}$ \\
\hline Intercept & $\begin{array}{l}-8.94 \\
(48.95)\end{array}$ & $\begin{array}{l}10.95 \\
(39.29)\end{array}$ & $\begin{array}{l}-5.69 \\
(54.48)\end{array}$ & $\begin{array}{l}-0.69 \\
(0.38)\end{array}$ \\
\hline \multicolumn{5}{|l|}{ Industry level variables } \\
\hline$E_{i-1, j k}$ & $\begin{array}{l}0.67 * * * \\
(0.25)\end{array}$ & $\begin{array}{l}0.23^{* * * *} \\
(0.09)\end{array}$ & $\begin{array}{l}0.39 * * * \\
(0.10)\end{array}$ & $\begin{array}{l}0.91 * * * \\
(0.02)\end{array}$ \\
\hline$Y_{i j k}$ & $\begin{array}{l}0.46^{* * *} \\
(0.14)\end{array}$ & $\begin{array}{l}0.41^{* * *} \\
(0.11)\end{array}$ & $\begin{array}{l}0.46^{* * *} \\
(0.15)\end{array}$ & $\begin{array}{l}0.06^{* * *} \\
(0.14)\end{array}$ \\
\hline$P_{i j k}$ & $\begin{array}{c}-0.30 * * * \\
(0.06)\end{array}$ & $\begin{array}{c}-0.21 * \\
(0.10)\end{array}$ & $\begin{array}{c}-0.33^{* * * *} \\
(0.08)\end{array}$ & $\begin{array}{c}-0.11^{* * *} \\
(0.02)\end{array}$ \\
\hline \multicolumn{5}{|l|}{ Country level variables } \\
\hline$Y_{k}^{c}$ & $\begin{array}{l}0.58^{* *} \\
(0.22)\end{array}$ & $\begin{array}{c}0.43 \\
(0.29)\end{array}$ & $\begin{array}{l}0.87 * * * \\
(0.29)\end{array}$ & $\begin{array}{l}0.17^{* * *} \\
(0.05)\end{array}$ \\
\hline$P_{k}^{c}$ & $\begin{array}{c}-0.29 * * * \\
(0.06)\end{array}$ & $\begin{array}{c}-0.36^{* * * *} \\
(0.14)\end{array}$ & $\begin{array}{c}-0.47^{* * *} \\
(0.13)\end{array}$ & $\begin{array}{c}-0.10^{* * * *} \\
(0.02)\end{array}$ \\
\hline \multicolumn{5}{|l|}{ Diagnostic Tests: } \\
\hline Arellano-Bond test AR(2) & 0.89 & 0.36 & 0.18 & 0.14 \\
\hline Sangan/Hansen test & 0.06 & 0.99 & 0.64 & 0.13 \\
\hline Hansen exogeneity Test & 0.98 & 0.99 & 0.12 & 0.13 \\
\hline Restriction test $\left(\mathrm{H} 0: D_{i}=0\right)$ & $\begin{array}{l}\chi^{2}(12)=75.5 \\
(0.00)^{* * *}\end{array}$ & $\begin{array}{l}\chi^{2}(12)=33.5 \\
(0.00)^{* * *}\end{array}$ & $\begin{array}{l}\chi^{2}(12)=46.0 \\
(0.00)^{* * *}\end{array}$ & $\begin{array}{l}\chi^{2}(12)=112.8 \\
(0.00)^{* * *}\end{array}$ \\
\hline Sample size & 12779 & 754 & 6006 & 6019 \\
\hline $\begin{array}{l}\text { Number of instruments } \\
\text { Long-run elasticities }\end{array}$ & 210 & 207 & 197 & 464 \\
\hline Income & $\begin{array}{c}1.41 \\
(0.74)\end{array}$ & $\begin{array}{c}0.54^{*} \\
(0.15)\end{array}$ & $\begin{array}{c}0.75^{*} \\
(0.18)\end{array}$ & $\begin{array}{c}0.68 * \\
(0.16)\end{array}$ \\
\hline Energy price & $\begin{array}{c}-0.91 \\
(0.61)\end{array}$ & $\begin{array}{c}-0.27 \\
(0.14)\end{array}$ & $\begin{array}{r}-0.54^{*} \\
(0.07)\end{array}$ & $\begin{array}{r}-1.21 * \\
(0.13)\end{array}$ \\
\hline
\end{tabular}

$* * *, * *$ and $*$ represent statistically significant at $0.1 \%, 1 \%$ and $5 \%$ level of significance respectively. $L R=$ $\frac{\delta_{x}}{1-e_{i-1, j k}} \quad x=Y_{i j k}, P_{i j k}$

Generally, we find the long-run output elasticities ranging from 0.54 to 1.41 to be larger than the estimated long-run price elasticities ranging from -0.27 to -1.21 . The relatively large value of the output elasticities to the price elasticities suggests that across all the classifications of sectors, industries are more sensitive to changes in economic activity than to changes in energy price in terms of their energy consumption.

\subsection{Discussion of the Estimated DMM Results}

We estimated Eq. (9) for the sector as a whole and for the sector types using the DMM and the results are reported in Table 3. Although, it is difficult to statistically demonstrate that the DMM is superior to the GMM in estimating an energy demand function, but we nonetheless again emphasize that the DMM controls for the hierarchical structure of the data used in this paper, and for this, we consider the DMM as the best modelling technique for our analysis. 
Table 3

Estimated dynamic multilevel model (DMM) (standard errors are in parentheses)

\begin{tabular}{|c|c|c|c|c|}
\hline Variables & $\begin{array}{l}\text { All } \\
\text { Sector }\end{array}$ & $\begin{array}{l}\text { Primary } \\
\text { Sector }\end{array}$ & $\begin{array}{l}\text { Manufacturing } \\
\text { Sector }\end{array}$ & $\begin{array}{l}\text { Service } \\
\text { Sector }\end{array}$ \\
\hline \multicolumn{5}{|l|}{ Fixed part: } \\
\hline Intercept & $\begin{array}{l}0.72^{* * *} \\
(0.09)\end{array}$ & $\begin{array}{l}1.12^{* * *} \\
(0.24)\end{array}$ & $\begin{array}{l}1.91^{* * *} \\
(1.15)\end{array}$ & $\begin{array}{l}1.10^{* * *} \\
(0.11)\end{array}$ \\
\hline \multicolumn{5}{|c|}{ Industry level variables } \\
\hline$E_{i-1, j k}$ & $\begin{array}{l}0.66^{* * *} \\
(0.01)\end{array}$ & $\begin{array}{l}0.57 * * * \\
(0.02)\end{array}$ & $\begin{array}{l}0.57^{* * *} \\
(0.01)\end{array}$ & $\begin{array}{l}0.69 * * * \\
(0.01)\end{array}$ \\
\hline$Y_{i j k}$ & $\begin{array}{l}0.28^{* * *} \\
(0.01)\end{array}$ & $\begin{array}{l}0.29 * * * \\
(0.02)\end{array}$ & $\begin{array}{l}0.36^{* * * *} \\
(0.01)\end{array}$ & $\begin{array}{l}0.18^{* * *} \\
(0.01)\end{array}$ \\
\hline$P_{i j k}$ & $\begin{array}{l}-0.23 * * * \\
(0.00)\end{array}$ & $\begin{array}{c}-0.22 * * * \\
(0.02)\end{array}$ & $\begin{array}{c}-0.33^{* * *} \\
(0.01)\end{array}$ & $\begin{array}{c}-0.15^{* * *} \\
(0.01)\end{array}$ \\
\hline \multicolumn{5}{|c|}{ Country level variables } \\
\hline$Y_{k}^{c}$ & $\begin{array}{l}0.29 * * * \\
(0.01)\end{array}$ & $\begin{array}{l}0.37 * * * \\
(0.03)\end{array}$ & $\begin{array}{l}0.25^{* * *} \\
(0.01)\end{array}$ & $\begin{array}{l}0.20 * * * \\
(0.01)\end{array}$ \\
\hline$P_{k}^{c}$ & $\begin{array}{l}-0.17^{* * *} \\
(0.01)\end{array}$ & $\begin{array}{c}-0.19 * * * \\
(0.01)\end{array}$ & $\begin{array}{c}-0.14^{* * *} \\
(0.01)\end{array}$ & $\begin{array}{c}-0.13^{* * *} \\
(0.01)\end{array}$ \\
\hline \multicolumn{5}{|l|}{ Random part: } \\
\hline$\sigma_{v}^{2}$ & $\begin{array}{c}0.09^{*} \\
(0.03)\end{array}$ & $\begin{array}{c}0.14^{*} \\
(0.04)\end{array}$ & $\begin{array}{c}0.15^{*} \\
(0.04)\end{array}$ & $\begin{array}{c}0.05^{*} \\
(0.02)\end{array}$ \\
\hline$\sigma_{u}^{2}$ & $\begin{array}{c}0.09 * \\
(0.00)\end{array}$ & $\begin{array}{c}0.03^{*} \\
(0.01)\end{array}$ & $\begin{array}{l}0.16^{*} \\
(0.02)\end{array}$ & $\begin{array}{c}0.06 \\
(0.01)\end{array}$ \\
\hline$\sigma_{\varepsilon}^{2}$ & $\begin{array}{l}0.03^{*} \\
(0.00)\end{array}$ & $\begin{array}{l}0.02 * \\
(0.00)\end{array}$ & $\begin{array}{l}0.03^{*} \\
(0.00)\end{array}$ & $\begin{array}{l}0.03^{*} \\
(0.00)\end{array}$ \\
\hline$\sigma_{0 \varepsilon}^{2}$ & $\begin{array}{l}0.44^{*} \\
(0.02)\end{array}$ & $\begin{array}{l}0.25^{*} \\
(0.05)\end{array}$ & $\begin{array}{l}0.35^{*} \\
(0.03)\end{array}$ & $\begin{array}{l}0.45^{*} \\
(0.03)\end{array}$ \\
\hline $\begin{array}{l}\text { ICC } \\
\text { Restriction tests }\end{array}$ & 0.44 & 0.74 & 0.44 & 0.39 \\
\hline $\mathrm{H} 0: D_{i}=0$ & $\begin{array}{l}\chi^{2}(13)=570.7 \\
(0.00)^{* * *}\end{array}$ & $\begin{array}{l}\chi^{2}(13)=80.8 \\
(0.00)^{* * *}\end{array}$ & $\begin{array}{l}\chi^{2}(13)=219.9 \\
(0.00)^{* * *}\end{array}$ & $\begin{array}{l}\chi^{2}(13)=342.2 \\
(0.00) * * *\end{array}$ \\
\hline $\mathrm{H} 0: \beta_{001}=\beta_{002}=0$ & $\begin{array}{l}\chi^{2}(2)=1260.5 \\
(0.00)^{* * *}\end{array}$ & $\begin{array}{l}\chi^{2}(2)=193.4 \\
(0.00)^{* * *}\end{array}$ & $\begin{array}{l}\chi^{2}(2)=354.4 \\
(0.00)^{* * *}\end{array}$ & $\begin{array}{l}\chi^{2}(2)=457.9 \\
(0.00) * * *\end{array}$ \\
\hline \multicolumn{5}{|c|}{ Long-run elasticities } \\
\hline Income & $\begin{array}{l}0.81 * \\
(0.02)\end{array}$ & $\begin{array}{l}0.67 * \\
(0.04)\end{array}$ & $\begin{array}{c}0.83^{*} \\
(0.02)\end{array}$ & $\begin{array}{c}0.58^{*} \\
(0.03)\end{array}$ \\
\hline Energy price & $\begin{array}{c}-0.68^{*} \\
(0.11)\end{array}$ & $\begin{array}{r}-0.52^{*} \\
(0.04)\end{array}$ & $\begin{array}{r}-0.77^{*} \\
(0.01)\end{array}$ & $\begin{array}{r}-0.49^{*} \\
(0.02)\end{array}$ \\
\hline
\end{tabular}

$* * *, * *$ and $*$ represent statistically significant at $0.1 \%, 1 \%$ and $5 \%$ level of significance. Intra-class correlation coefficient $(I C C)=\frac{\sigma_{v}^{2}}{\sigma_{v}^{2}+\sigma_{u}^{2}+\sigma_{\varepsilon}^{2}}$ and $L R=\frac{\delta_{x}}{1-e_{i-1, j k}} \quad x=Y_{i j k}, P_{i j k}$

The DMM results reported in Table 3 consist of the fixed part where the estimates of the explanatory variables estimated are presented and the random part where the results of the random unobserved heterogeneity are presented. Unlike the GMM, all estimated parameters of the DMM are statistically significant with expected signs inclusive the estimates of the random part. As carried out in the GMM, we also test for the importance for allowing for the underlying nonlinear factor in the DMM using the $\chi^{2}$-Test. The DMM results across all sector types also support for allowing for the underlying nonlinear factors while estimating energy demand by rejecting the null hypothesis that the coefficients on the time dummies are 
statistically equal to zero (that is, $\mathrm{H} 0: \beta_{100}=0$ ) at $0.1 \%$ significant level. The primary results derived from the DMM models estimated are as follows.

First, the statistical significance of the coefficients on all the country-level variables reported in Table 3 for the whole sector and sector types emphasize the important roles of aggregate activities on industrial energy use. Given the statistical significance of the contextual variables, the result suggests that industries are not operating in isolation as aggregate economic activities evidenced to influence the energy consumption of industries. For robustness check on the importance of the country-level explanatory variables in the models estimated, we perform a restriction test using the $\chi^{2}$-Test to test the null hypothesis that the coefficients on the country-level variables are jointly statistically not different from zero (that is, H0: $\beta_{001}=\beta_{002}=0$ ). In all models estimated, our results reject the null hypothesis that the contextual variables are not statistically different from zero at $0.1 \%$ level of significance. This outcome thus reinforces the importance of controlling for the country-level variables while estimating industrial energy demand with industry-level data as failure to do so may lead to biased energy demand elasticities. Second, the difference between the size of the within-country and between-country elasticities provides important information about the extent of the relationship between energy and the explanatory variables. Across board, the relationship between energy and output is the same at industry-level and country-level by looking at the difference between the average of the within-country output elasticity 0.27 and between-country output elasticity 0.27. However, this is not the case if will consider individual sector type. For instance, for the primary sector, the relative size of the withincountry income elasticity 0.29 to its corresponding between-country income elasticity 0.37 indicates that the relationship between energy and income is stronger at the aggregate level than industry level, but otherwise in the manufacturing sector. In general, the within-country price elasticity is larger in value than its corresponding between-country price elasticity in all models estimated. For price elasticity across board, the average elasticity of the withincountry price 0.23 and its corresponding average elasticity of the between-country price 0.16 suggest that the relationship between energy and own-price is stronger at the industry level by $7 \%$. One possible explanation for this might be that industries are more sensitive to changes in local energy prices as they can alter their input use combination than a change in national energy price.

In addition, we can also infer from the results reported in Table 3 that the values of the estimated short-run price elasticities and short-run output elasticities for the all sectors 
and primary sector are somewhat similar. However, this is not the case in comparison, especially with the short-run elasticities for the service sector as the short-run elasticities for the manufacturing sector in some cases somewhat similar in values to that of the all sectors and the primary sector ${ }^{20}$. For instance, the short-run estimated within-country output elasticity for the all sectors and the primary sector are 0.28 and 0.29 respectively. This result indicates that a $10 \%$ increase in output is associated with about $2.8 \%$ and $2.9 \%$ increase in the energy consumption of the all sector and primary sector respectively. This suggests that the impact of a change in the economic activity on the energy consumption of the primary sector and that of European industry as a whole is almost the same. The implication of this result is that a change in energy consumption of the primary sector is largely associated with a change in the energy consumption of the European industry as the degree of responsiveness of the primary industry resulting from a change in price or output is similar to that of the industry as a whole. For the price elasticity, the short-run estimated within-country price elasticity for the all sectors and primary sector are -0.23 and -0.22 respectively, suggesting that a $10 \%$ rise in energy price is associated with about $2.2 \%$ and $2.3 \%$ reduction in energy consumption of the sectors as a whole and the primary sector respectively.

We now focus on the results of the random part of the estimated DMM reported in Table 3. The information provided by the results of the random part allows us to demonstrate the strengths of multilevel modelling in terms of its ability to account for and separate the unobserved heterogeneity at different levels of the data, which single-level models such as GMM and fixed effect will overlook. As argued earlier, we would like to emphasize that failure to account for the cluster level of the data may lead to unreliable estimates. The results of the random part reported in Table 3 explain the unobserved cluster level heterogeneity in our models. The disturbance terms $\sigma_{v}^{2}, \sigma_{u}^{2}$ and $\sigma_{\varepsilon}^{2}$ represent country-differences, industrydifferences and time-differences and they measure the changes in energy consumption with respect to differences in- country, industry and time respectively. Our results show that all estimated disturbance terms reported in Table 3 are statistically significant. Specifically for the whole sector, although, the statistical significance of the coefficients on unobserved terms $\sigma_{v}^{2}=0.09, \sigma_{u}^{2}=0.09$ and $\sigma_{\varepsilon}^{2}=0.03$ demonstrate the importance of country, industry and time variations to changes in European industrial energy consumption, but we are very much interested to measure the role of country differences in energy consumption. To measure the

\footnotetext{
${ }^{20}$ We do not find this kind of similarity in the estimated GMM reported in Table 2 as we find the short-run elasticities across different models estimated to be considerably differs in most cases.
} 
extent of contextual effects in determine European industrial energy consumption, we employ the intra-class correlation coefficient (ICC). The coefficient of the ICC 0.44 suggests that $44 \%$ of the unexplained variations in industrial energy use in Europe are traceable to betweencountry differences. In other words, the differences in energy use by industries are to some reasonable extent affected by aggregate indicators.

The ICC for the manufacturing and service sectors are very similar to that of the whole sector, implies that the differences in energy use of these sectors are to some meaningful extent characterised by aggregate activities. However, the results of the random part of the primary sector prove otherwise as the ICC (0.74) suggests that about $74 \%$ of the unobserved variations in energy use of the primary sector are traceable to between-country differences rather than between-industry difference. In other words, industries in the primary sector are largely tied to their respective country. One possible explanation for this strong relationship between the primary sector and their respective aggregate activities may be as a result of the strong role of the government in industries such as the agriculture, fishing and forestry, which form the major part of the primary sector. For this reason, they are likely to be more sensitive to changes in macroeconomic policies ${ }^{21}$.

The estimated long-run elasticities derived from energy demand functions have retained energy demand modelling as an important area of interest in the literature. This is because these elasticities have served as important tools for the policy makers in making appropriate predictions about future energy use and energy related policies. This subsequently highlights the potential implications of energy related policies based on inaccurate estimates, which are very likely to be misleading or inappropriate. In respect to this argument, we now discuss the estimated long-run income and price elasticities reported in Table 3. Unlike the estimated GMM long-run elasticities, all estimated DMM long-run elasticities reported in Table 3 are statistically significant with expected signs. Our results show that the European industrial energy demand is income-inelastic with an estimated long-run elasticity 0.81 and also priceinelastic with estimated price elasticity -0.68 . The results indicate that a $10 \%$ rise in income and in price is associated with $8.1 \%$ rise and $6.8 \%$ reduction respectively in European industrial energy consumption on average in the long-run. In terms of the elasticity of economic activity, our value is similar to that of Dimitropoulous et al. (2005). Our income

\footnotetext{
${ }^{21}$ Interestingly, The Economist (2017) emphasised the danger for the UK farmers that they may be among the first to feel the effects of Brexit as UK agriculture is heavily reliant of foreign workers and they may not be available for long.
} 
elasticity 0.81 is almost the same of the average income elasticity 0.76 for the UK manufacturing and transport sector obtained in Dimitropoulous et al. (2005). However, they obtained average price elasticity -0.11 , a value smaller to ours -0.68 . The value of our longrun price elasticity -0.68 is almost identical to the price elasticity -0.64 obtained in Agnolucci (2009) for the British and German industrial sector ${ }^{22}$.

The relative big value of the estimated income elasticity (0.81) compare to the price elasticity $(-0.68)$ in absolute terms suggests that European industrial energy demand is more responsive to changes in economic activity than to changes in energy price. For the subsectors, we find the price elasticity of energy demand for the primary, manufacturing and service sectors to $0.67,0.83$ and 0.58 respectively. Further, the long-run price elasticities for these sectors are $-0.54,-0.77$ and -0.49 respectively. The results show that the long-run elasticities of the manufacturing sector are markedly higher than the long-run elasticities of other sector types. This is reasonable as we would expect the largest energy consuming sector (manufacturing) to be more sensitive to changes in energy price and economic activity than other sectors.

By comparing the long-run elasticities of the sector types, our results show that the DMM long-run output elasticities reported in Table 3 are somewhat similar in values to that of the GMM, reported in Table 2. However, with the exception of the service sector, the estimated DMM long-run price elasticities for the primary $(-0.52)$ and manufacturing $(-0.77)$ sectors are bigger in absolute value than their corresponding estimated long-run price elasticities derived from the GMM $(-0.27,-0.54)$. Therefore, in general, one would have expected the estimated GMM long-run price elasticity -0.91 for the whole sector (however, not statistically significant) to be smaller than that of the DMM -0.68 in absolute terms, but it is otherwise. This is due to the large value of the service's sector price elasticity -1.21 reported in Table 2. This is an intriguing finding suggesting that estimates derived from a model using industry-level data that fails to control for the multilevel structure of the data may be unreliable as in the case of the GMM. Further, the whole sector's estimated long-run income 1.41 derived from the GMM, though, not statistically significant is again larger the value obtained in DMM 0.81. This further reinforces our argument that failure to account for the

\footnotetext{
${ }^{22}$ However, we advised that one should be exercise caution when comparing our estimates to Dimitropoulous et al. (2005) and Agnolucci (2009) due to differences in scope, data and econometric methodology employed.
} 
underlying multilevel structure of the data may lead to unreliable estimates in form of overestimation or underestimation.

\section{Concluding Remarks}

Given the pivotal role energy plays in the process of economic development and the continuation of economic growth, especially in modern industrialised countries, its absence or shortage (of course) is expected to cause nothing but a serious damage to the production processes and consequently retards economic growth and standard of living. However, rapid economic growth or sustainable growth is associated with an increase in energy use that typically results in higher carbon and particulate emissions. The devastating impact of increasing emissions therefore requires accurate projections of future energy demand, which are necessary in order to understand and address issues relating to energy security, resource planning, trans-boundary emissions, etc. Thus, the improved energy demand parameters provided by our dynamic multilevel modelling approach should be seen as significant tools for policymakers.

In this paper, we employed a dynamic multilevel model and GMM estimator to analyse industrial energy demand across European countries for the period 1995 - 2009. Our energy demand models allow for the underlying non-linear forces that might influence our energy demand estimates as pointed out in the literature. In all models estimated, our findings are in the body of evidence in the literature by supporting the fact that it is important to allow for the inherent underlying non-linear forces in the energy demand model. Further, to a meaningful extent, we confirm that the DMM performs better than the GMM in terms of the estimated parameters that are statistically significant. Moreover, we would also like to reiterate that, unlike the GMM, our dynamic multilevel model controls for the hierarchical structure of the data used in the analysis by assigning disturbance terms to each level of the data. Given the aforementioned advantages of the DMM over the GMM within the context of this study, we chose the DMM as our preferred choice of modelling technique.

Our preferred model finds European industrial energy consumption to significantly influence by the country-level variables as all country-level variables estimated are statistically significant. This is actually reinforced by the result of ICC in the DMM (0.44), suggesting that about $44 \%$ of the unexplained variations in industrial energy consumption are traceable to between-country differences. Moreover, we find European industrial energy demand to be both income- and price-inelastic with estimated long-run elasticities of 0.81 and -0.68 
respectively. However, the long-run elasticities generated from the alternative model, although not statistically significant, but are substantially overestimated with estimated income and price elasticity 1.41 and -0.91 respectively. This is an intriguing finding demonstrating that unless energy demand models using industry-level data are formulated so as to allow for the multilevel structure of the data, the estimated income and price elasticities could be seriously biased. Our finding has a serious implication that policy based on such wrong or inaccurate energy demand estimates is very likely to be misleading or inappropriate. In particular, as our preferred model indicates relatively large long-run income elasticity, this suggests that European industries are more responsive to changes in economic activities. However, despite the relatively lower estimated long-run price elasticity in our preferred model, the results still suggest that policy responses influencing energy prices are likely to be effective in reducing energy consumption. More importantly, our results suggest that controlling for the hierarchical structure of the energy data is imperative if we wish to make more appropriate predictions about future energy use and associated carbon emissions in Europe. In addition, this paper has not simply introduced a new method of modelling energy demand, but also highlights the need for more sophisticated modelling of energy demand if policy makers seek to formulate appropriate policies related to energy security and climate change. We therefore hope that future research will draw on our approach and focus on estimating energy demand households provided that there is appropriate data available. 


\section{References}

Adeyemi, O.I., Hunt, L.C., 2007. Modelling OECD industrial energy demand: asymmetric price responses and energy-saving technical change. Energy Econ. 29 (4), 693-709.

Adeyemi, O.I., Hunt, L.C., 2014. Accounting for asymmetric price responses and underlying energy demand trends in OECD industrial energy demand. Energy Econ. 45, 435-444.

Adeyemi, O.I., Broadstock, D.C., Chitnis, M., Hunt, L.C., Judge, G., 2010. Asymmetric price responses and the underlying energy demand trend: Are they substitutes or complements? Evidence from modelling OECD aggregate energy demand. Energy Econ. 32 (5), 1157-1164.

Agnolucci, P., 2009. The energy demand in the British and German industrial sectors: Heterogeneity and common factors. Energy Econ. 31 (1) 175-187.

Agnolucci, P., 2009. Stochastic trends and technical change: the case of energy consumption in the British industrial and domestic sectors. Energy J. 31(4), 111-135

Agnolluci, P., De Lipsis, V., Arvanitopoloulos, T., 2017. Modelling UK sub-sector industrial energy demand. Energy Econ. 67, 366-374.

Anderson, R., 1981. On the specification of conditional factor demand functions in recent studies of U.S. manufacturing. In: Berndt ER, Field BC (Eds), Modeling and measuring natural resources substitution. MIT Press, Cambridge, Massachusetts. 119-144.

Arnberg, S., Bjørner, T.B., 2007. Substitution between energy, capital and labour within industrial companies: a micro panel data analysis. Resour. Energy Econ. 29, 122-136.

Arellano, M., Bond, S., 1991. Some tests of specification for panel data: Monte Carlo evidence and an application to employment equations. Rev. Econ. Stu. 58 (2), 277-297.

Berndt, E.R., Wood, D.O., 1975. Technology, prices, and the derived demand for energy. Rev. Econ. Stat. 57 (3), 259-268.

Bhattacharyya, S.C., 2011. Energy Demand Analysis at a Disaggregated Level. In: Energy EconomicsConcepts, Issues, Markets and Governance. 77-106.

Bjørner, T., Jensen, H., 2002. Energy taxes, voluntary agreements and investment subsidies—a micro-panel analysis of the effect on Danish industrial companies' energy demand. Resour. Energy Econ. 24 (3), 229249.

Raudenbush, S.W., Bryk, A.S., 2002. Hierarchical linear models: Applications and data analysis methods. 2nd ed. Thousand Oaks, CA: Sage

Crouchley, R., Stott, D., Pritchard, J., 2009. Multivariate Generalised Linear Mixed Models via sabreStata (Sabre in Stata) University of Lancaster.

Dargay, J., Gately, D., 1995. The imperfect price reversibility of non-transport oil demand in the OECD. Energy Econ. 17 (1), 59-71.

Dilaver, Z., Hunt, L.C., 2011. Industrial electricity demand for Turkey: a structural time series analysis. Energy Econ. 33, 426-436.

Dimitropoulos, J., Hunt, L.C., Judge, G., 2005. Estimating underlying energy demand trends using UK annual data. Appl. Econ. Letts. 12 (4), 239-244.

Floros, N., Vlachou, A., 2005. Energy demand and energy-related CO2 emissions in Greek manufacturing: assessing the impact of a carbon tax. Energy Econ. 27 (3), 387-413

Filippini, M., Hunt, L.C., 2011. Energy demand and energy efficiency in the OECD countries: a stochastic demand frontier approach. Energy J. 32 (2), 59-80.

Fuss, M.A., 1977. The demand for energy in Canadian manufacturing: An example of the estimation of production structures with many inputs. J. Econometrics. 5 (1), 89-116.

Gately, D., Huntington, H.G., 2002. The asymmetric effects of changes in price and income on energy and oil demand. Energy J. 23 (1), 19-55. 
Greening, L., Boyd, G., Roop, J., 2007. Modelling of industrial energy consumption: an introduction and context. Energy Econ. 29 (4), 599-608.

Griffin, J.M., Gregory, P.R., 1976. An intercountry translog model of energy substitution responses. Am. Econ. Rev. 66, 845-857.

Griffin, J.M., Schulman, C.T., 2005. Price asymmetry in energy demand models: a proxy for energy-saving technical change? Energy J. 26 (2), 1-21.

Haas, R., Schipper, L. 1998. Residential energy demand in OECD-countries and the role of irreversible efficiency improvements. Energy Econ. 20 (4), 421-442.

Haller, S.A., Hyland, S., 2014. Capital-energy substitution: Evidence from a panel of Irish manufacturing firms. Energy Econ. 45, 501-510.

Harvey, A., 1989. Forecasting, Structural Time Series Models and the Kalman Filter. University Press, Cambridge, Cambridge.

Heckman, J.J., 1981. The incidental parameters problem and the problem of initial conditions in estimating a discrete time- discrete data stochastic process. In Structural Analysis of Discrete Data with Econometric Applications (eds C.F. Manski and D.L. McFadden), pp. 179-195. Cambridge: MIT Press.

Hox, J.J., Moerbeek, M., van de Schoot, R., 2010. Multilevel analysis: Techniques and applications (Quantitative Methodology Series). ${ }^{\text {nd }}$ Ed. Routledge Ltd.

Hunt, L.C., Ninomiya, Y., 2005. Primary energy demand in Japan: an empirical analysis of long-term trends and future CO 2 emissions. Energy Pol. 33(11), 1409-1424.

Hunt, L.C.,Judge, G.,Ninomiya, Y., 2003a. Underlying trends and seasonality in UK energy demand: a sectoral analysis. Energy Econ. 25, 93-118.

Huntington, H., 2006. A note on price asymmetry as induced technical change. Energy J. 27 (3), 1-7.

Islam, M.K, Merio, J., Kawachi, I., Lindstr, M., Burstr\&ouml;m, K., Gerdtham, U., 2006. Does it really matter where you live? A panel data multilevel analysis of Swedish municipality-level social capital on individual health-related quality of life. Health Econ. Policy. Law. 1 (03), 209-235.

Kazemi, I., Crouchley, R., 2006. Modelling the initial conditions in dynamic regression models of panel data with random effects. Contrib. Econ. Anal. 274, 91-117.

Kim, J., Heo, E., 2013. Asymmetric substitutability between energy and capital: Evidence from the manufacturing sectors in 10 OECD countries. Energy Econ. 40, 81-89.

Konishi, C., Hymel, S., Zumbo, B.D., Li, Z. 2010. Do school bullying and student-teacher relationships matter for academic achievement? A multilevel analysis. Can. J. Schl. Psychol. 25 (1), 19-39.

Layte, R. 2011. The association between income inequality and mental health: testing status anxiety, social capital, and neo-materialist explanations. Eur. Sociol. Rev. jcr 012, 1-14.

Lee, K., (1997). Modelling economic growth in the UK: An econometric case for disaggregated sectoral analysis. Econ. Model. 14 (3), 369-394.

Lee, C., Lee, J., 2010. A panel data analysis of the demand for total energy and electricity in OECD countries. Energy J. 31 (1), 1-23.

Lee, C., Chiu, Y., 2011. Electricity demand elasticities and temperature: Evidence from panel smooth transition regression with instrumental variable approach. Energy Econ. 33 (5), 896-902.

Lee, C., Chiu, Y., 2013. Modelling OECD energy demand: An international panel smooth transition errorcorrection model. Int. Rev. Econ. Fin. 25, 372-383.

Lin, B., Ahmad, I., 2016. Technical change, inter-factor and inter-fuel substitution possibilities in Pakistan: a trans-log production function approach. J. Cleaner. Prod.126, 537-549.

Li, J., Lin, B., 2016. Inter-factor/inter-fuel substitution, carbon intensity, and energy-related CO2 reduction: Empirical evidence from China. Energy Econ. 56, 483-494.

Medlock III, K.B., 2009. Energy demand theory. In: International Handbook on the Economics of Energy. Edward Elgar. 89-111.

Mohnen, S.M., Groenewegen, P.P., Völker, B., Flap, H., 2011. Neighbourhood social capital and individual health. Soc. Sci. Med. 72 (5), 660-667. 
Murayama, H., Fujiwara, Y., Kawachi, I., 2012. Social capital and health: a review of prospective multilevel studies. J. Epid. 22 (3), 179-187.

Nickell, S., 1981. Biases in Dynamic Models with Fixed Effects. Econometrica 49 (6), 1417-1426.

Pesaran, M.H., Smith, R.P., Akiyama, T., 1998. Energy demand in Asian developing economies. Oxford University Press.

Prywes, M., 1986. A nested CES approach to capital-energy substitution. Energy Econ. 8 (1), 22-28

Rabe-Hesketh S., Skrondal A., 2012. Multilevel and Longitudinal Modeling Using Stata. Third Edition. Volume I: Continuous Responses. College Station, Texas: Stata Press.

Rabe-Hesketh, S., Skrondal, S., 2014. Handling initial conditions and endogenous covariates in dynamic/transition models for binary data with unobserved heterogeneity. Appl. Stat.-J. Roy. St. C. 63 (2), 211-237.

Rentfrow, P.J., Gosling, S.D., Jokela, M., Stillwell, D.J., Kosinski, M., Potter, J. 2013. Divided we stand: Three psychological regions of the United States and their political, economic, social, and health correlates. J. Pers. Soc. Psychol. 105 (6), 996-1012.

Robinson, W.S., 2009. Ecological correlations and the behaviour of individuals. Int. J. Epid. 38 (2), 337-341.

Ronfeldt, M., Loeb, S., Wyckoff, J. 2013. How teacher turnover harms student achievement. Am. Educ. Res. J. vol. 50 (1), 4-36.

Srholec, M., 2010. A multilevel approach to geography of innovation. Reg. Stud. 44 (9), 1207-1220.

Steele, F., 2008. Multilevel models for longitudinal data. J. Roy. Stat. Soc. A. Sta. 171 (1), 5-19.

Steele, F., Rasbash, J., Jenkins, J., 2013. A multilevel simultaneous equations model for within-cluster dynamic effects, with an application to reciprocal parent-child and sibling effects. Psychol. Methods. 18 (1), 87-100.

Steele, F., 2014. Multilevel Modelling of Repeated Measures Data. LEMMA VLE Module 15, 1-62.

Steenbergen, M.R., Jones, B.S., 2002. Modeling multilevel data structures. Am. J. Polit. Sci. 46 (1), 218-237.

The Economist. 2017. Farmers may be among the first to feel the effects of Brexit (Print Edition) Feb. 232017.

Tovas, M.A, Iglesias, E.M, 2013. Capital-energy relationships: an analysis when disaggregating by industry and different types of capital. Energy J. 34, 129-150.

Tso, G.K., Guan, J., 2014. A multilevel regression approach to understand effects of environment indicators and household features on residential energy consumption. Energy. 66, 722-731.

Uri, N.D., 1982. The industrial demand for energy. Socio. Econ. Plan. Sci. 16 (2), 69-84.

Voyer, D., Voyer, S.D. 2014. Gender differences in scholastic achievement: A meta-analysis. Psychol. Bull. 140 (4), 1174.

York, R., 2007. Demographic trends and energy consumption in European Union Nations, 1960-2025. Soc. Sci. Res. 36 (3), 855-872.

\section{Appendix A1}

To show the importance of the response at first period let consider a simple dynamic multilevel model for simplicity.

$$
E_{i, j}=\beta_{1}+\delta E_{i-1, j}+\beta_{2} x_{i, j}+u_{j} \epsilon_{i, j}
$$

Eq. (A.12) is only for time periods $i>1$ because the value of the lagged response at period 1 is unknown. The model for the response at $i=2$ is 


$$
E_{2, j}=\beta_{1}+\delta E_{1, j}+\beta_{2} x_{1, j}+u_{j}+\epsilon_{2, j}
$$

and by substituting Eq. (A.12) for the expression $E_{2, j}$ in model for the response at $i=3$, we derive

$$
\begin{aligned}
E_{3, j} & =\beta_{1}+\delta E_{2, j}+\beta_{2} x_{2, j}+u_{j}+\epsilon_{3, j} \\
& =\beta_{1}+\delta\left(\beta_{1}+\delta e_{1, j}+\beta_{2} x_{1, j}+u_{j}+\epsilon_{2, j}\right)+\beta_{2} x_{2, j}+u_{j}+\epsilon_{3, j} \\
& =(1+\delta) \beta_{1}+\delta^{2} E_{1, j}+\left(\delta x_{1, j}+x_{2, j}\right) \beta_{2}+(1+\delta) u_{j}+\delta \epsilon_{2, j}+\epsilon_{3, j}
\end{aligned}
$$

Eq. (A.13) displays the importance of time period 1 as model $E_{3, j}$ can be re-specified in which it depends on $E_{1, j}$ with coefficient $\delta^{2}$. Therefore, by continuing the substitution process it is straightforward to show that the response $E_{k, j}$ at any period $k(k=2, \ldots, T)$

\begin{tabular}{|c|c|c|}
\hline $\mathbf{S} / \mathbf{N}$ & $\begin{array}{l}\text { NACE } \\
\text { Description }\end{array}$ & Sector \\
\hline 1 & secAtB & Agriculture, Hunting, Forestry and Fishing \\
\hline 2 & secC & Mining and Quarrying \\
\hline 3 & sec15t16 & Food, Beverages and Tobacco \\
\hline 4 & sec17t18 & Textiles and Textile Products \\
\hline 5 & sec19 & Leather, Leather and Footwear \\
\hline 6 & sec20 & Wood and Products of Wood and Cork \\
\hline 7 & sec21t22 & Pulp, Paper, Paper , Printing and Publishing \\
\hline 8 & sec23 & Coke, Refined Petroleum and Nuclear Fuel \\
\hline 9 & sec24 & Chemicals and Chemical Products \\
\hline 10 & sec25 & Rubber and Plastics \\
\hline 11 & sec26 & Other Non-Metallic Mineral \\
\hline 12 & sec27t28 & Basic Metals and Fabricated Metal \\
\hline 13 & sec29 & Machinery, Nec \\
\hline 14 & sec30t33 & Electrical and Optical Equipment \\
\hline 15 & sec34t35 & Transport Equipment \\
\hline 16 & sec36t37 & Manufacturing, Nec; Recycling \\
\hline 17 & secE & Electricity, Gas and Water Supply \\
\hline 18 & secF & Construction \\
\hline 19 & sec50 & Sale, Maintenance and Repair of Motor Vehicles and Motorcycles; Retail Sale of Fuel \\
\hline 20 & sec51 & Wholesale Trade and Commission Trade, Except of Motor Vehicles and Motorcycles \\
\hline 21 & sec52 & Retail Trade, Except of Motor Vehicles and Motorcycles; Repair of Household Goods \\
\hline 22 & secH & Hotels and Restaurants \\
\hline 23 & sec60 & Inland Transport \\
\hline 24 & sec61 & Water Transport \\
\hline
\end{tabular}
depends on $E_{1, j}$ with coefficient $\delta^{k-1}$.

\section{Appendix A2}

List of ISIC Rev.4 (NACE Rev.2) Sectors 


\begin{tabular}{|l|l|l|}
\hline 25 & sec62 & Air Transport \\
\hline 26 & sec62 & Other Supporting and Auxiliary Transport Activities; Activities of Travel Agencies \\
\hline 27 & sec64 & Post and Telecommunications \\
\hline 28 & secJ & Financial Intermediation \\
\hline 29 & sec70 & Real Estate Activities \\
\hline 30 & sec71t74 & Renting of M\&Eq and Other Business Activities \\
\hline 31 & secL & Public Admin and Defence; Compulsory Social Security \\
\hline 32 & secM & Education \\
\hline 33 & secN & Health and Social Work \\
\hline 34 & secO & Other Community, Social and Personal Services \\
\hline
\end{tabular}

Notes: based on the NACE classification, the industries could be classified into: primary sector which consists of S/N 1 to 2, manufacturing sector consists of S/N 3 to 18 and service sector consists of S/N 19 to 34.

\section{Appendix A3}

Assuming a standard multilevel model where only level 1 and level 2 variables are considered for simplicity is written as:

$$
E_{i, j}=\beta_{1}+\beta_{2} x_{i, j}+\beta_{3} x_{2, j}+u_{j}+\epsilon_{i, j}
$$

where level 1 variable is $x_{i, j}$ and level 2 variable is $x_{2, j}$. If the level 2 variable is the mean of level 1 variable (as the case of this study) that is also included in the model, Eq. (A.21) becomes

$$
E_{i, j}=\beta_{1}+\beta_{2} x_{i, j}+\beta_{3} \bar{x}_{j}+u_{j}+\epsilon_{i, j}
$$

where $\bar{x}$ is the mean of $x$ in group $j$. In Eq. (A.22) $\beta_{2}$ is the within-group effect of $x$ and $\beta_{2}+$ $\beta_{3}$ is the between-group effect of $x . \beta_{2}$ measures the relationship between an individual's $x$ and $E$ values within group while $\beta_{2}+\beta_{3}$ captures the effect of the group mean of $x$ on the group mean of $E$. $\beta_{2}$ measures the contextual effect of the group mean of $x$ on an individual $e$ that is over and above the effect of an individual $x$ on $E$. The problem with Eq. (A.22) is that estimate of the between-group effect cannot be estimated directly. In order to get a direct estimate and standard error for the between-group effect of $x, x_{i, j}$ is transformed to $x_{i j}-\bar{x}_{j}$ which is called group mean centring, then Eq. (A.22) is therefore re-specified as:

$$
E_{i, j}=\beta_{1}^{*}+\beta_{2}^{*}\left(x_{i, j}-\bar{x}_{j}\right)+\beta_{3}^{*} \bar{x}_{j}+u_{j}+\epsilon_{i, j}
$$

where the within-group effect equals $\beta_{2}^{*}=\beta_{2}$, and $\beta_{3}^{*}=\beta_{2}+\beta_{3}$ is the between-group effect. 